\title{
Novel Techniques for Investigating the High Temperature Degradation of Protective Coatings on Nickel Base Superalloys
}

\author{
A.A.Alibhai, D.P Garriga-Majo, B.A Shollock, D.S. McPhail \\ Department of Materials, Imperial College of Science, Technology and Medicine, \\ Prince Consort Road, London, SW7 2BP
}

\begin{abstract}
In order to facilitate improved fuel efficiency and power to weight performance in gas turbines, components are subjected to increasing operating temperatures. The demanding operating conditions have lead to the development of coating systems, which protect the gas turbine components from environmentally induced attack. The effectiveness of the coating relies on the mechanism by which a healing oxide scale is formed and replaced during thermal cycling. Therefore, in order to optimise coating performance, it is vital to develop a clear understanding of the oxidation mechanisms involved during scale formation. [1]

Novel approaches involving ${ }^{18} \mathrm{O}_{2}$ isotopic tracer experiments, secondary ion mass spectrometry (SIMS) and focused ion beam (FIB) in-situ milling, have been employed to investigate the high temperature oxidation mechanisms of various commercial protective coatings on industrial gas turbines and other nickel base superalloy systems. These techniques lend themselves well to the study of high temperature degradation, as they are able to provide essential information on the diffusion pathways of oxygen anions and metal cations during oxide formation [2-3].

In the first part of this study, the use of a two-stage tracer oxidation technique and Secondary Ion Mass Spectrometry have been employed to investigate the oxygen diffusion mechanisms occurring during scale formation on uncoated superalloys CMSX4 and $\mathrm{CM} 186 \mathrm{LC}$ at temperatures between $826^{\circ} \mathrm{C}$ to $1100^{\circ} \mathrm{C}$.
\end{abstract}

The cation depth profiles obtained give information regarding the chemical nature of the oxides formed and these results provide a baseline against which the oxidation performance of coatings may be assessed.

In the second part of this study, oxides formed on a platinum aluminide coating $\mathrm{MDC150 \textrm {L }}$ which had been oxidised at $870^{\circ} \mathrm{C}$, have been analysed by micromaching cross sections of the oxide layer using a $\mathrm{Ga}^{+}$focused ion beam (FIB-FEI Europe) instrument. These cross sections were analysed on the FIB, using secondary ion and electron imaging, and oxygen mapping.

Results from this study have provided essential information regarding the microstructural evolution of the oxide layer during high temperature exposure, revealing the oxide thickness and isotopic oxygen distribution. For uncoated superalloy CM186LC, outward cation diffusion was observed for all temperatures between $820^{\circ} \mathrm{C}$ and $1100^{\circ} \mathrm{C}$. In the case of superalloy CMSX4, outward cation diffusion occurred at temperatures up to $996^{\circ} \mathrm{C}$. Above $996^{\circ} \mathrm{C}$ a change in mechanism was observed and combination of outward cation and inward oxygen diffusion occurs. For the coating system MDC150L, outward cation diffusion is observed at $870^{\circ} \mathrm{C}$, for extended oxidation periods up to 82 hours, and the coating formed an effective alumina scale.

These encouraging results obtained have highlighted the usefulness of the focused ion beam technique and secondary ion mass spectroscopy in elucidating the high temperature degradation of protective coatings and nickel base superalloys. 


\section{Introduction}

Thermal barrier coating (IBC) systems are typically applied to hot section components of gas turbine engines in order to reduce part temperatures and improve component durability. TBC systems involve a ceramic top coat, which is most commonly yttria-stabilised zirconia (YSZ) due to its poor thermal conductivity and good coefficient of thermal expansion. An underlying metallic bond coat is applied between the superalloy substrate and the ceramic top coat. This bond coat must be resistant to high temperature oxidation as the ceramic top coat does not act as a barrier to oxygen and hence does not protect the substrate alloy. The metallic bond coat is designed to form a protective and adherent $\alpha-\mathrm{Al}_{2} \mathrm{O}_{3}$ scale. Spallation of this thermally grown alumina scale leads to the loss of the ceramic top coat and ultimately failure of the TBC system. Various studies [4-6] have shown that the oxidation mechanism of the metallic bond coat is a key aspect in determining the useful lifetime of TBC systems.

The use of isotopic tracer experiments and conventional Secondary Ion Mass Spectrometry (SIMS) has extensively been reported for the study of high temperature oxidation [7], especially for alumina forming systems [2,8-12]. These studies, combined with results obtained from other techniques such as $\mathrm{X}$ Ray diffraction, Rutherford Backscattering Spectrometry and Transmission Electron Microscopy [13-14], have emphasised the possible complexity of the oxide scale growth mechanism, which may involve oxygen and/or cationic diffusion through different pathways and also phase transformations within the oxide scale.

Focused Ion Beam (FIB) technology has recently been applied to the investigation of the high temperature degradation of industrial turbine blades [15] and coatings [16]. FIB technology is routinely used within the semiconductor industry and has only recently been used in other application areas such as specimen preparation for biological electron microscopy [17], multilayer optical oxide/nitride films, hard carbide coating on tool steels [18], and $\mathrm{Al}-\mathrm{Li}-\mathrm{Cu}$ quasicrystal investigations [19]. A major advantage of the application of the FIB system to the study of high temperature oxidation is its capability to perform in situ micro-machining (ion milling) of the specimen and to prepare cleaned surfaces for high resolution SIMS analysis and imaging.

'The recent developments in high Z-resolution microscopes such as the Atomic Force Microscope and Interferometric Optical Microscopes have made it possible to obtain valuable information regarding the oxide surface properties as well depth calibration of the SIMS craters.

In this paper, novel approaches towards investigating the high temperature oxidation of uncouted superalloys and coating systems are introduced. Investigation of uncoated substrate alloys is useful as it provides information regarding the durability of the bare superalloy in the event of coating failure. It also provides a foundation on which the oxidation performance of coatings may be assessed. In this study, the high temperature isothermal oxidation of uncoated single crystal CMSX4 (Cannon Muskegon) and directionally solidified alloy CM186LC (Cannon Muskegon) were investigated using the two-stage isotopic tracer technique and SIMS analysis. Oxide scales formed on a platinum modified aluminide coating MDC150L (Howmet-Thermatech) were analysed using a focused ion beam system (FIB200) and micromaching cross-sections of the oxide. Analysis of the oxide layer was performed using secondary electron and secondary ion imaging, oxygen mapping and depth profiling.

\section{Experimental Procedure}

\section{Materials}

Uncoated superalloys CMSX4 and CM186LC were studied at oxidation temperatures between $826^{\circ} \mathrm{C}$ and $1100^{\circ} \mathrm{C}$ for a total of 22 hours. These alloys have virtually the same chemical composition, with small differences in elements added to aid the directionally solidified process. Table 1 gives the chemical composition of these superalloys.

A platinum modified aluminide coating MDC150L applied to the directionally solidified alloy CM186LC using a low aluminium activity- chemical vapour deposition process [20] was also investigated for various oxidation periods at $870^{\circ} \mathrm{C}$. This coating has a single phase (Ni,Al)Pt additive layer. Beneath this is a well developed diffusion zone, which is almost one third of the total coating thickness, and is characteristic of an outward grown coating. Typically, the total coating thickness (post heat treatment) is $77.5 \mu \mathrm{m}$ and the coating composition is $19.5 \mathrm{wt} . \% \mathrm{Al}$ and $19.0 \mathrm{wt} . \% \mathrm{Pt}$.

\section{Specimen preparation}

In the case of the uncoated superalloys samples were cut with specimen orientation normal to the $\langle 100\rangle$ plane. For alloy CM186LC, specimen orientation was determined via X-Ray Diffraction texture analysis using the Phillips X'Pert Materials Research Diffractometer (MRD). In the case of the single crystal alloy CMSX4, back reflection Laue was performed using a $30 \mathrm{kV}$ voltage and a $30 \mathrm{~mm}$ film to specimen distance. Samples were then sliced normal to the $<100\rangle$ plane using the Accutom 5 cutting machine (Struers). Samples were then polished to $1 \mu \mathrm{m}$ and cleaned ultrasonically in acetone for 20 minutes.

The MDC150L/CM186LC system was received as a fatigue test specimen, which had previously been oxidised for 20 hours in air at $870^{\circ} \mathrm{C}$. Small samples were cut for analysis as described above.

\section{Oxidation Study}

A two-stage oxidation treatment was performed on all the samples. In this tracer oxidation technique, the sample was first oxidised in one isotope of oxygen with an ${ }^{18} \mathrm{O}_{2}$ partial pressure of $g_{1}$, for a period of time $t_{1}$, thus forming the first oxide layer. The sample was then oxidised in the tracer isotope with an ${ }^{18} \mathrm{O}_{2}$ partial pressure of $g_{2}$ for a period of time $t_{2}$, thus forming the new oxide. Uncoated samples CMSX4 and CM186LC were first oxidised for 18 hours in ${ }^{18} \mathrm{O}_{2}$ (enriched to $50 \%, \mathrm{~g}_{1}=0.5$ ), followed by 4 hours in unlabelled ${ }^{16} \mathrm{O}_{2}\left(g_{2}=0.002\right)$, at temperatures between $826^{\circ} \mathrm{C}$ and $1100^{\circ} \mathrm{C}$. The coated samples MDC150L on alloy CM186LC were first oxidised in air $\left(\mathrm{g}_{\mathrm{l}}=0.002\right)$ for 20 hours at $870^{\circ} \mathrm{C}$ (as received condition). The samples were then further oxidised in ${ }^{18} \mathrm{O}_{2}$ (enriched to $87 \%, g_{2}=0.87$ ) for 4 hours and 62 hours at the same temperature. All oxidations took place at 200 millibar pressure and the sample tube was briefly evacuated between anneals. Table 2 summarises the oxidation treatments and the SIMS and FIB experiments performed on the uncoated superalloys CMSX4 and CM186LC and the coating MDC150L. 


\begin{tabular}{|c|c|c|c|c|c|c|c|c|c|c|c|c|c|}
\hline ALLOY & \multicolumn{10}{|c|}{ COMPOSITIONAL DATA } \\
\hline & $\mathrm{Ni}$ & $\mathrm{Hf}$ & $\mathrm{C}$ & $\mathrm{Cr}$ & $\mathrm{Co}$ & $\mathrm{Mo}$ & $\mathrm{W}$ & $\mathrm{Re}$ & $\mathrm{Ta}$ & $\mathrm{A} 1$ & $\mathrm{Ti}$ & $\mathrm{B}$ & $\mathrm{Zr}$ \\
\hline $\mathrm{CM} 86 \mathrm{LC}$ & $\mathrm{bal}$ & 1.4 & 0.07 & 6.0 & 9.0 & 0.5 & 8.4 & 3.0 & 3.4 & 5.7 & 0.7 & 0.015 & 0.015 \\
\hline CMSX4 & $\mathrm{bal}$ & 0.1 & 0.1 & 6.5 & 9.0 & 0.6 & 6.0 & 3.0 & 6.5 & 5.6 & 1.0 & - & - \\
\hline
\end{tabular}

Table 1: Compositional Data (wt \%) for alloys CMSX4 and CM186LC, which were investigated in the two-stage isotopic oxidation study.

\section{Secondary Ion Mass Spectroscopy}

SIMS depth profiling is an extremely useful technique for analysing the tracer oxygen diffusion mechanisms in metal systems, as it is able to distinguish all the isotopes in the periodic table. Although this is a destructive surface analysis technique, it combines very high depth resolution with exceptional detection limits (typically parts per million). This technique involves a mono-energetic focused beam of primary ions (typically $0.25 \mathrm{keV}$ to $15 \mathrm{keV}$ ), bombarding the surface of a solid sample in a vacuum. The momentum transfer between the incoming ions and the constituent atoms leads to the emittance of secondary species from the surface of the material. This process is known as sputtering. The sputtered species may be neutral or charged particles. The charged particles are detected and analysed using conventional mass spectrometry analysis. As the ion beam continually rasters across the surface of the sample, it sputters material from the surface thus forming a square crater.

In this study SIMS depth profiling measurements were conducted on the oxidised superalloy samples using the ATOMIKA 6500 Ion Microprobe. A Xenon $\left(\mathrm{Xe}^{+}\right)$primary ion beam was used to raster the surface of the sample at near normal incidence, with a primary beam energy of either $8 \mathrm{keV}$ or $15 \mathrm{keV}$. Negative secondary ions of ${ }^{16} \mathrm{O}^{-}$and ${ }^{18} \mathrm{O}^{-}$were monitorcd as a function of time for all samples. During analysis of the uncoated samples, metal ions such as ${ }^{27} \mathrm{Al}^{-},{ }^{59} \mathrm{Co}^{-},{ }^{58} \mathrm{Ni}^{-}$and ${ }^{52} \mathrm{Cr}^{-}$were also monitored. Scan widths of between $250 \mu \mathrm{m}$ and $300 \mu \mathrm{m}$ were employed and secondary ions were gated to $25 \%$ of the total raster area in order to avoid any crater wall effects.

\section{The Focussed Ion Beam System}

The focussed ion beam system (FIB200-FEI UK Ltd.) works in essentially the same manner as conventional SIMS, but in this case the FIB200 employs a gallium $\mathrm{Ga}^{+}$liquid metal ion source, which operates at $30 \mathrm{keV}$. The size of the beam can be preprogrammed depending on the beam current used and typically a beam diameter of just a few nanometers can be achieved using a current of approximately 1 picoampere. Typically, high currents (few $n A$ ) are used to mill different shapes of crater and smaller currents (few pA) permit high resolution SIMS analysis. In order to prevent surface charging a thin layer of platinum (typically $1 \mu \mathrm{m})$ may be deposited in-situ.

The FIB200 system is equipped with different detectors:

- a secondary electron detector.

- a channeltron (CDEM) used to detect secondary ions and high energy electrons for imaging.
- a quadrupole mass spectrometer for SIMS analysis (mass spectrum, depth profiling, elemental mapping).

The Gat primary beam generates a low secondary ion signal compared to conventional ion sources such as $\mathrm{O}_{2}{ }^{+}$and $\mathrm{Xe}^{+}$, but it offers a very high spatial ability. The different motions of the stage $\mathrm{X}, \mathrm{Y}, \mathrm{Z}$, rotation and tilt can be followed using an optical camera.

In this study oxides formed on the coated sample MDC150L wcre analysed by ion milling cross sections of the oxide and performing secondary electron imaging and isotopic oxygen mapping. The oxide surface was coated with platinum in order to avoid any surface charging. Depth profiling using the FIB200 was also performed on all the oxides grown on the coated samplc.

\section{Depth Calibration}

Depth calibration of the profiles was performed using a $Z$-high resolution microscope (Zygo) and an Atomic Force Microscope (Quesant Resolver), by measuring the total depth of the craters and assuming a constant sputter rate throughout the oxide scale.

\section{Deternination of Tracer Enrichment}

In order to be able to compensate for any undesirable variations in secondary ion intensities due to surface charging, the isotopic fractions $i r_{18}$ and $i r_{16}$ are plotted as a function of depth. Neglecting any contribution from ${ }^{17} \mathrm{O}^{-}$, which has a natural abundance of $0.037 \%$, the isotopic fractions for oxygen 18 and oxygen 16 are given as: $i r_{18}=\frac{{ }^{18} O^{-}}{{ }^{18} O^{-}+{ }^{16} O^{-}}$and $i r_{16}=1-i r_{18}$ respectively.

These isotopic fractions reflect the actual isotopic concentration variations in the oxide scale. In order to quantify the relative isotope tracer enrichment in the oxide scale, the parameter $v$ was estimated for the oxidation treatments performed and is given by:

$$
v=\frac{i r_{18}-g_{1}}{g_{2}-g_{1}}
$$

where $g_{1}$ and $g_{2}$ are the ${ }^{18} \mathrm{O}_{2}$ partial pressure in the first and second oxidation atmospheres respectively. By plotting the tracer enrichment parameter $v$ as a function of depth, it is possible to distinguish the regions where the new oxide has grown. Regions of pure new oxide growth have a v-value of unity, whereas regions of old oxide growth have values of zero. Regions that contain a mixture of new and old oxide have a $v$-value between 0 and 1. 


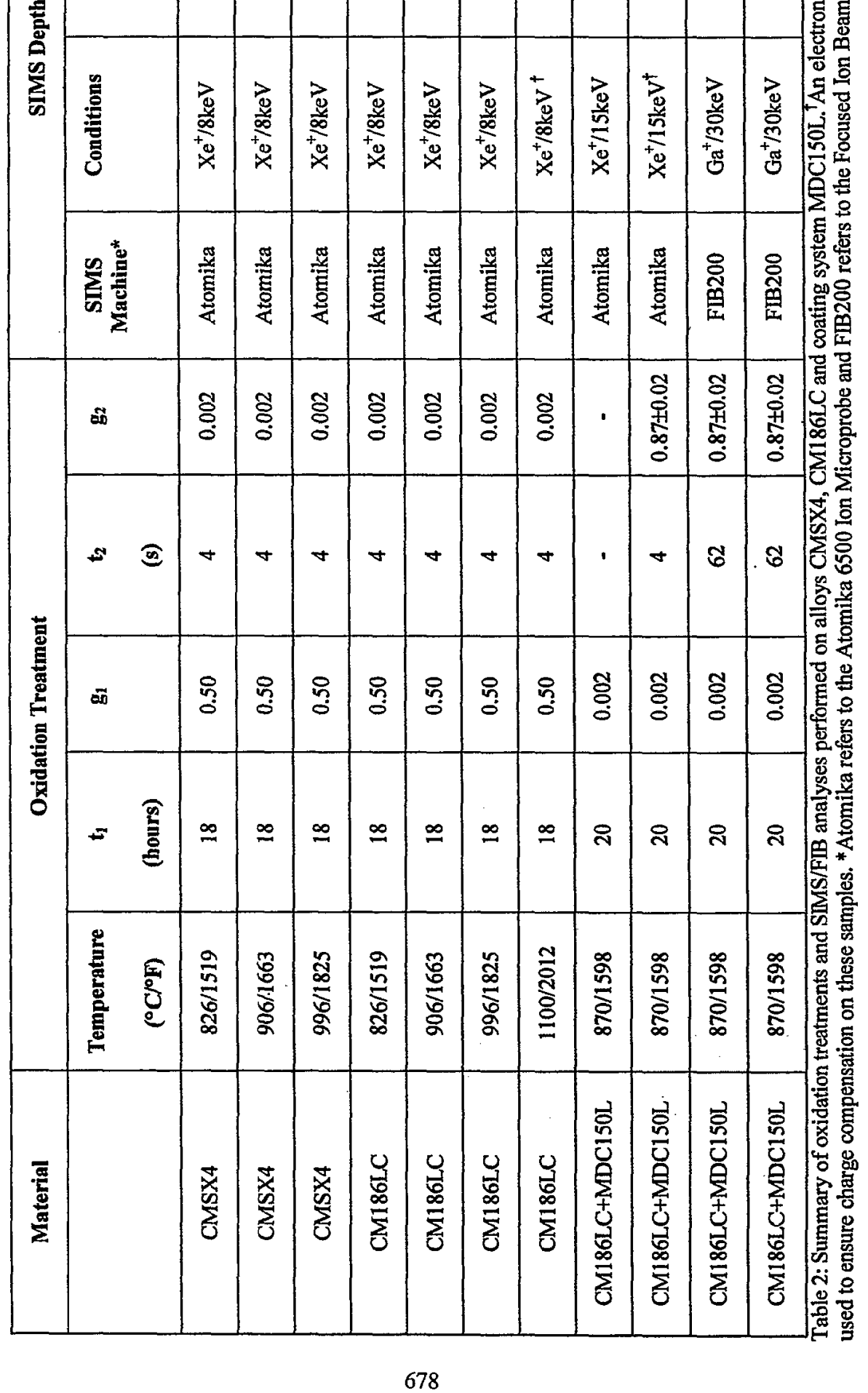


Depending on the oxidation temperature and the superalloy substrate, the diffusion of the tracer and the further growth of the oxide may take place at one of these three locations:

1. At the gas/oxide interface with a new oxide growth of thickness $\mathrm{d}_{\mathrm{g}}$.

2. Within the oxide formed during the first thermal treatment, the thickness of this new oxide layer is called $d_{o}$.

3. At the oxide/metal interface with a new growth of thickness $\mathrm{d}_{\mathrm{m}}$

The total oxide thickness is typically determined by the depth over which the sum of the two negative oxygen secondary ion intensitics falls to half its maximum value and is denoted as $d_{0.5}$. An example of this is given in figure 1 for alloy CMSX4 oxidised at $996^{\circ} \mathrm{C}$ and values of $d_{0.5}$ are given in table 3 .

The cation diffusion mechanisms are presented as normalised secondary ion intensities. These are determined by dividing the negative metal secondary ion count rate at profiling time $t$ over the maximum negative secondary ion count rate for that metal species. This method allows the relative variation of each metal species in the oxide to be displayed. Examples of cation depth profiles for CM186LC and CMSX4 oxidised at $996^{\circ} \mathrm{C}$ for total oxidation periods up to 22 hours are given in figures 2 and 4 .

\section{$\underline{\text { Results }}$}

\section{Uncoated Superalloys}

Values for the total oxide thickness $d_{0.5}$ and regions of new and partially new tracer oxide thickness at the gas/oxide interface $\left(d_{g}\right)$, metal/oxide interface $\left(d_{m}\right)$ and within the existing oxide $\left(d_{o}\right)$ are given in Table 3 , as well as the predominant oxidation mechanisms that occur in superalloys CMSX4 and CM186LC which have been oxidised for 18 hours in ${ }^{18} \mathrm{O}_{2}$, followed by 4 hours in ${ }^{16} \mathrm{O}_{2}$. The average oxide growth rate for these superalloys for each temperature has been determined by dividing the total oxide thickness $\mathrm{d}_{0.5}$, by the total oxidation time, which is 1320 minutes ( 22 hours) in all cases. The oxygen depth profile for alloy CMSX4 oxidised at $996^{\circ} \mathrm{C}$, for 18 hours in ${ }^{18} \mathrm{O}_{2}$, followed by 4 hours in ${ }^{16} \mathrm{O}_{2}$ is shown in figure 1 .
The depth over which the sum of the oxygen 18 and oxygen 16 ions falls to half its maximum value, is one possible method of determining the total oxide scale.

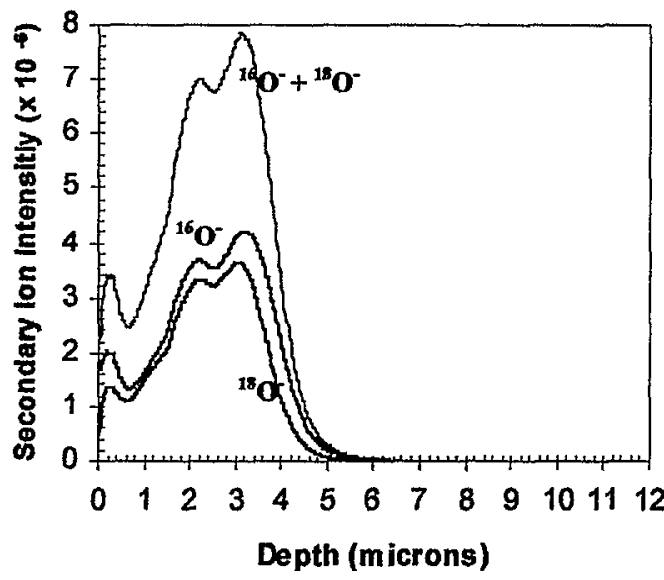

Figure 1: Oxygen depth profile for sample CMSX4 oxidised at $996^{\circ} \mathrm{C}$. The total oxide thickness $d_{0}$ occurs at $4.2 \mu \mathrm{m}$, which is the depth at which the sum of the ${ }^{18} \mathrm{O}^{-}$and ${ }^{16} \mathrm{O}^{-}$falls to half its maximum

\begin{tabular}{|c|c|c|c|c|c|c|c|}
\hline \multirow[t]{2}{*}{ Alloy } & \multirow{2}{*}{$\begin{array}{c}\text { Oxidation } \\
\text { Temperature } \\
\left({ }^{\circ} \mathrm{C}\right)\end{array}$} & \multirow{2}{*}{ 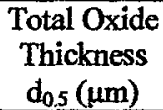 } & \multirow{2}{*}{$\begin{array}{c}\text { Average } \\
\text { Growth Rate } \\
\text { (nm/min) }\end{array}$} & \multicolumn{3}{|c|}{ New Oxide Growth } & \multirow[t]{2}{*}{ Oxidation Mechanism } \\
\hline & & & & $\begin{array}{c}d_{\mathrm{g}} \\
(\mu \mathrm{m})\end{array}$ & $\begin{array}{c}\mathrm{d}_{\mathrm{o}} \\
(\mathrm{pem})\end{array}$ & $\begin{array}{c}d_{m} \\
(\mu \mathrm{m})\end{array}$ & \\
\hline CMSX4 & 826 & 1.2 & 0.91 & 0.1 & - & - & \multirow[b]{2}{*}{ Outward Cation Diffusion } \\
\hline CMSX4 & 906 & 3.2 & 2.42 & 0.15 & 1.0 & - & \\
\hline $\mathrm{CMSX}^{\dagger}$ & 996 & 4.2 & 3.71 & 0.5 & - & 1.0 & $\begin{array}{l}\text { Combination of Outward } \\
\text { Cation and Inward } \\
\text { Oxygen Diffusion }\end{array}$ \\
\hline$\overline{C M 186 L C}$ & 826 & 1.4 & 1.06 & 0.2 & - & - & \multirow{4}{*}{ Outward Cation Diffusion } \\
\hline CM186LC & 906 & 5.5 & 4.17 & 1.2 & - & - & \\
\hline CM186LC & 996 & 7.0 & 5.30 & 1.6 & - & - & \\
\hline CM186LC & 1100 & 12.0 & 9.0 & 4.8 & - & - & \\
\hline
\end{tabular}

Table 3: Summary of results for CMSX4 and CM186LC showing where the tracer oxide has formed and predominant oxidation mechanism. "Cation depth profiles and tracer enrichment profiles for CM186LC for these conditions are shown in figures 2 and 3 respectively. Cation depth profiles and tracer enrichment profiles for CMSX4 for these conditions are shown in figures 4 and 5 respectively. 


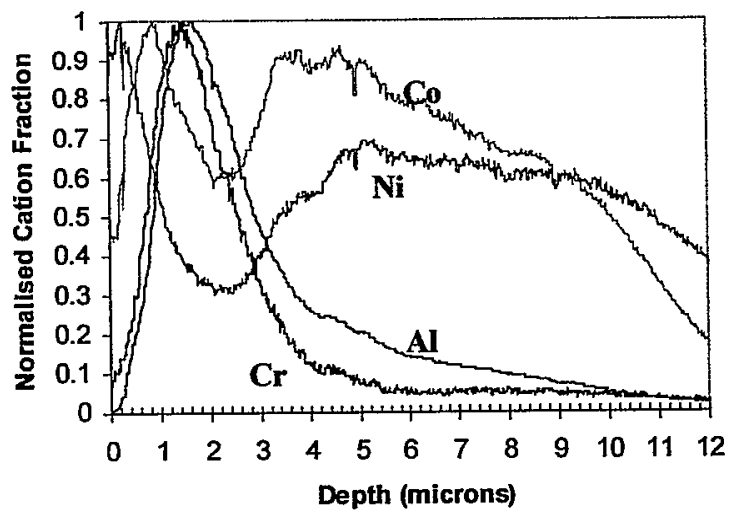

Figure 2: Normalised cation depth profile for CM186LC oxidised at $996^{\circ} \mathrm{C}$ for 18 hours in ${ }^{18} \mathrm{O}_{2}$ and 4 hours in ${ }^{16} \mathrm{O}_{2}$.

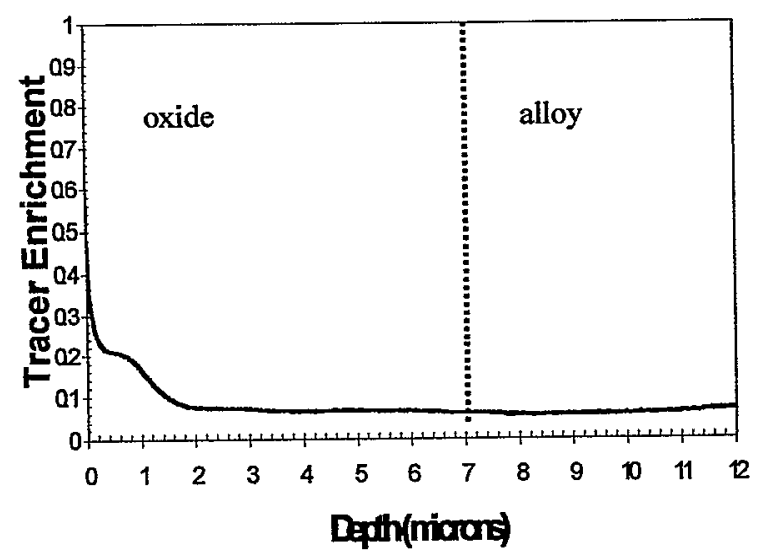

Figure 3: Tracer enrichment profile for CM186LC oxidised at $996^{\circ} \mathrm{C}$ as for figure 2 .

\section{Coating MDC150L}

Total oxide thickness $d_{0.5}$, average oxide growth rate and the predominant oxidation mechanism that occurs for the coating system $\mathrm{MDC} 150 \mathrm{~L}$ at $870^{\circ} \mathrm{C}$ for oxidation in air for 20 hours and various periods up to 62 hours in ${ }^{18} \mathrm{O}_{2}$ are given in Table 4 .

\begin{tabular}{|c|c|c|c|}
\hline $\begin{array}{c}\text { Oxidation Time } \\
\text { (hours) }\end{array}$ & $\begin{array}{c}\text { Total } \\
\text { Oxide } \\
\text { thickness } \\
(\mu \mathrm{m})\end{array}$ & $\begin{array}{c}\text { Average } \\
\text { Growth } \\
\text { Rate } \\
(\mathrm{nm} / \mathrm{min})\end{array}$ & $\begin{array}{c}\text { Predominant } \\
\text { Oxidation } \\
\text { Mechanism }\end{array}$ \\
\hline 20 hours air & 0.5 & 0.41 & $\begin{array}{c}\text { Outward Cation } \\
\text { Diffusion }\end{array}$ \\
\hline $\begin{array}{c}20 \text { hours air }+ \\
4 \text { hours }{ }^{18} \mathrm{O}_{2}\end{array}$ & 0.55 & 0.39 & $\begin{array}{c}\text { Outward Cation } \\
\text { Diffusion }\end{array}$ \\
\hline 20 hours air + & 0.95 & 0.19 & $\begin{array}{c}\text { Outward Cation } \\
\text { Diffusion }\end{array}$ \\
\hline 4 hours ${ }^{18} \mathrm{O}_{2}$ & & &
\end{tabular}

Table 4: Summary of results obtained for coating MDC150L oxidised at $870^{\circ} \mathrm{C}$.



Figure 4: Normalised cation depth profile for CMSX4 oxidised at $996^{\circ} \mathrm{C} 18$ hours in ${ }^{18} \mathrm{O}_{2}$ and 4 hours in ${ }^{16} \mathrm{O}_{2}$.



Figure 5: Tracer enrichment profile for CMSX4 oxidised at $996^{\circ} \mathrm{C}$ as for figure 4 .

Imaging results from the focused ion beam study for the coating MDC150L which had been oxidised in air for 20 hours and then 62 hours in ${ }^{18} \mathrm{O}_{2}$ at $870^{\circ} \mathrm{C}$ are given in figures 6 and 8 to 11 . The oxide morphology is shown in figure 6 , which is a secondary electron image of the crater wall formed after depth profiling. Figure 7 is a schematic diagram showing the direction the gallium beam during in-situ ion milling and imaging which was used to obtain figures 8 to 11 . Figure 8 is a secondary ion image of the surface of the oxide formed on the coating, and the position of the wedge crater, which was formed using the $\mathrm{Ga}^{+}$beam. The oxide surface above the crater was coated with platinum in order to avoid any surface charging effects. This also helps to clearly define the top of the oxide surface. Figure 9 is a secondary electron image and is an enlargement of the grain boundary area shown figure 8. Figures 10 and 11 are ${ }^{16} \mathrm{O}^{-}$and ${ }^{18} \mathrm{O}^{-}$maps respectively and correspond to the same region shown in figure 9. 


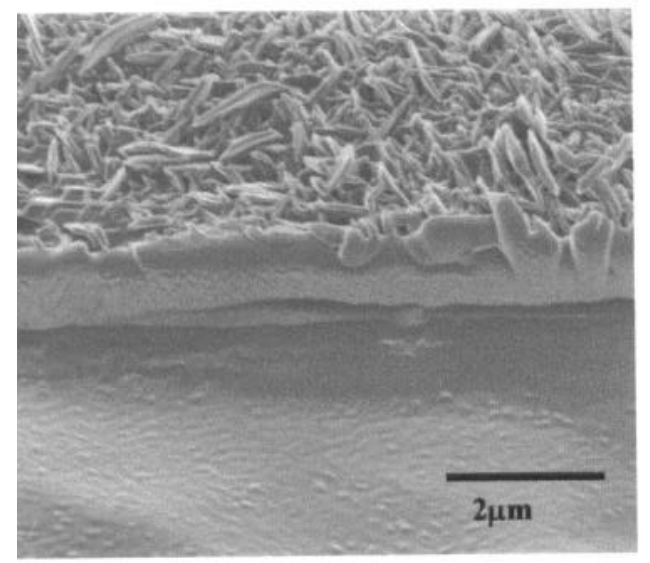

igure 6: Secondary electron image of the crater wall formed fter depth profiling revealing a $\theta-\mathrm{Al}_{2} \mathrm{O}_{3}$ whisker morphology on re oxide surface.

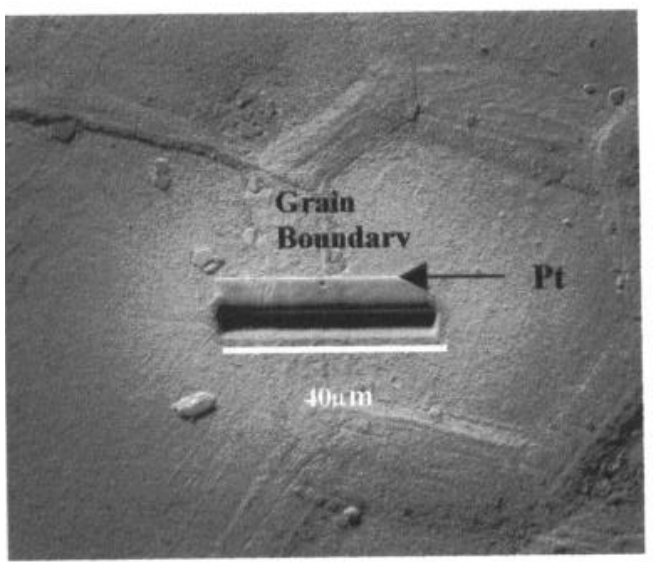

Figure 8: Secondary ion image of the ion-milled crater made on he oxide formed on coating MDC150L oxidised at $870^{\circ} \mathrm{C}$ for 20 hours in air plus 62 hours in ${ }^{18} \mathrm{O}_{2}$. Platinum was deposited above the crater in order to avoid any surface charging effects. The hexagonal grain structure of the coating can also be seen.

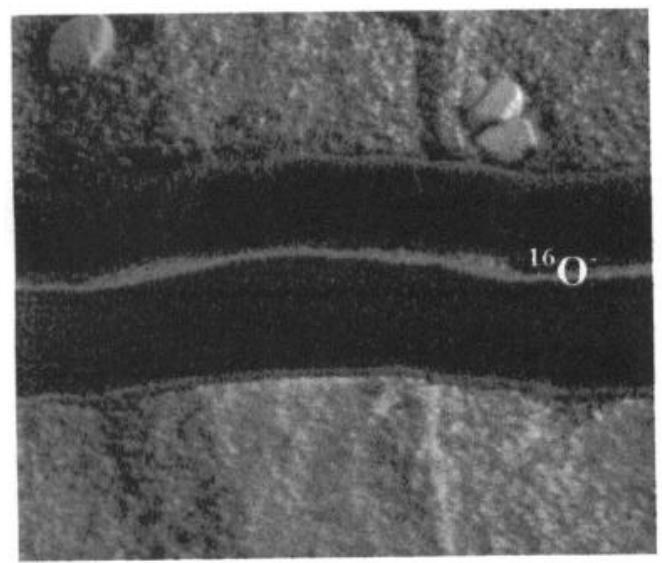

Figure $10:{ }^{16} \mathrm{O}^{-}$elemental map over the grain boundary region shown in figure 6.

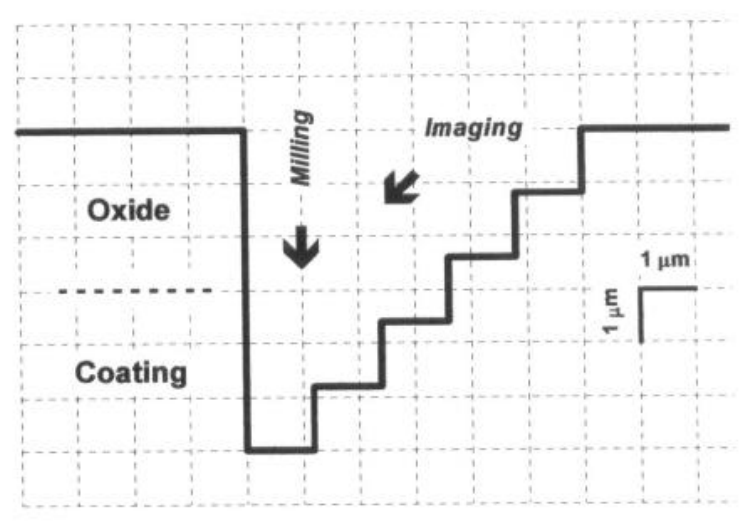

Figure 7: Schematic diagram showing the direction of the $\mathrm{Ga}^{+}$ ion beam during in-situ ion milling and imaging.

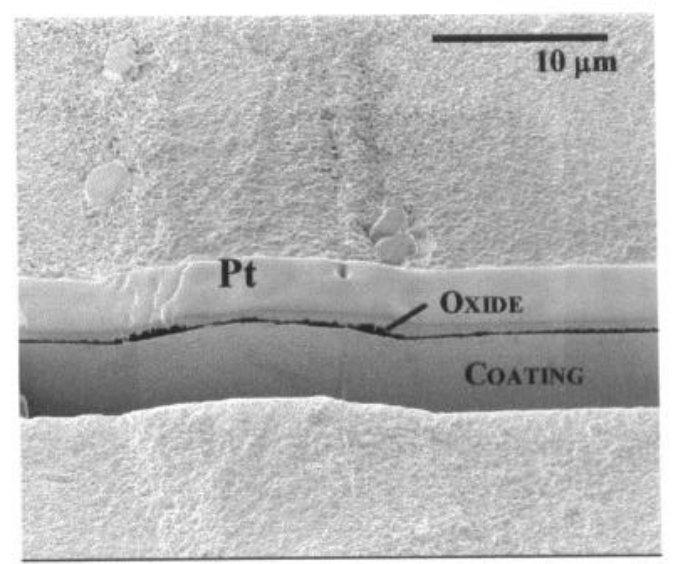

Figure 9: A general view of the milled cross-section. (Secondary electron image, tilt $45^{\circ}$ ).

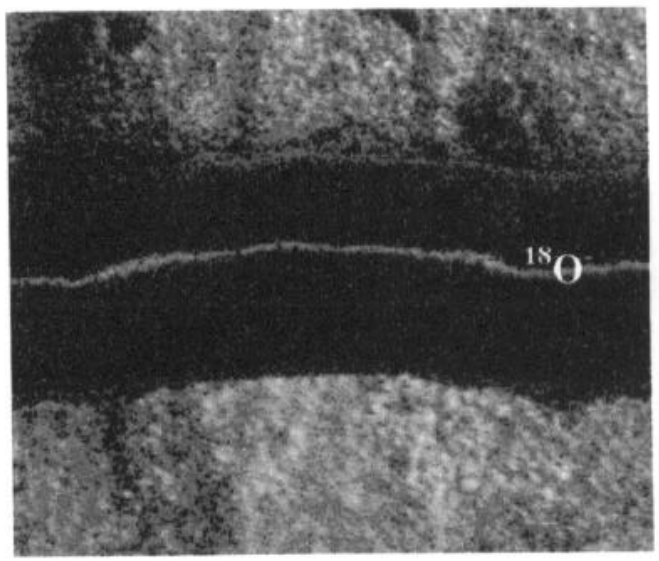

Figure 11: ${ }^{18} \mathrm{O}^{-}$elemental map over the same region as shown in figure 8 . 


\section{Discussion}

\section{Uncoated Superalloys}

With respect to the tracer oxidation study made on the uncoated superalloys CMSX4 and CM186LC (given in figure 2 and 3), a number of key observations can be made. Results for alloys CM186LC show that outward cation diffusion is the predominant oxidation mechanism for all temperatures between $826^{\circ} \mathrm{C}$ and $1100^{\circ} \mathrm{C}$. This is shown in the example given in figure 3 . The tracer enrichment parameter $v$ is high at the gas-oxide interface indicating possible surface exchange and new oxide growth. Also, with the exception of the oxide formed at $826^{\circ} \mathrm{C}$, the total oxide thicknesses are significantly greater for the directional solidified alloy CM186LC compared to those grown on the single crystal alloy CMSX4. Samples for both these superalloys have been cut normal to the $\langle 100\rangle$ orientation and hence this result may be attributed to fast oxygen diffusion down grain boundaries in the dircctional solidified alloy CM186LC. Such a result is comparable to hot oxidation tests performed by others [22-23] on these alloys.

With respect to the total oxide thickness values $d_{0.5}$ given in tables 3 and 4, it is important to note that this value often gives an underestimate of the true oxide thickness as can be seen for alloy CM186LC, which has been oxidised at $996^{\circ} \mathrm{C}$. The $\mathrm{d}_{0.5}$ value for this sample is found to be $7.0 \mu \mathrm{m}$, although the cation diffusion profile at this point is still in the nickel and cobalt plateau. An alternative method for determining the total oxide thickness would be to evaluate the regions of new and old oxide growth at the gas-oxide, old oxide, and oxidc-metal interface from the tracer enrichment profile. However, as it is not always possible to determine the oxide growth at the oxide-metal interface (as shown in figure 3), this method is limited. Hence, the total oxide thickness $d_{0.5}$ found from the sum of the oxygen profiles remains an adequate method for determining the total oxide thickness.

The cation diffusion profiles for this alloy also provide interesting information with regard to the nature of the oxides that form. Figure 2 is an example of a normalised cation diffusion profile obtained for this alloy at $996^{\circ} \mathrm{C}$. This shows that the oxide at the gas-oxide interface is nickel rich and most likely to be NiO. A middle oxide layer is cobalt rich and the rest of the oxide near the oxide-alloy interface is rich in aluminium and chromium. The nickel plateau observed at depths greater than $5 \mu \mathrm{m}$ indicates a third extended oxide region, which is also rich in cobalt. Although the SIMS technique does not provide quantitative information on the oxide composition, such cation diffusion depth profiles are very useful as they provide information regarding the nature of the oxide formed.

The results obtained for CMSX4 show that a change in oxidation mechanism is observed at $996^{\circ} \mathrm{C}$. At lower temperatures, this alloy displays outward cation diffusion. However, at $996^{\circ} \mathrm{C}$ the mechanism is altered and a combination of inward oxygen and outward cation diffusion through the first oxide layer is observed. Figure 5 shows the tracer enrichment profile for this alloy, which has been oxidised at $996^{\circ} \mathrm{C}$. This shows an area of high tracer enrichment at the gas-oxide interface and represents a new growth in this region. It is also interesting to note that in figures 3 and 5 the tracer enrichment does not fall to zero, which may simply represent background enrichment. However, it is plausible that this may correspond to the tracer having exchanged into the previous oxide grains or formed a new phase within the previous oxides grain boundaries. Such behaviour is as predicted by others [21], who have performed such two stage isotopic tracer experiments on alumina forming alloys. The tracer enrichment value then increases to a plateau with a $v$-value of 0.42 , which indicates a region of new oxide growth within the existing oxide. At the oxide-metal interface the tracer enrichment value begins to rise as ${ }^{16} \mathrm{O}_{2}$ gas has been used as the tracer gas. The noise in the rising tail of the profile is characteristic of profiling into the substrate alloy.

The normalised cation depth profile in figure 4 for alloy CMSX4, which has been oxidised at $996^{\circ} \mathrm{C}$ shows that the region closest to the gas oxide surface is nickel rich, indicating nickel cation diffusion through the oxide to this interface. The central oxide is a mixture of nickel, cobalt and chromium oxide, beneath which a large region of an aluminium rich oxide exists. All the normalised cation fractions tail off towards zero and indicate profiling into the substrate. This is due to the fact that during the SIMS depth profiling, ionisation of the negative cation species takes place more readily in the oxide compared to the superalloy substrate and so low secondary ion counts are obtained in the substrate.

A key observation to be made from these results is that for both superalloys investigated in this study, neither alloy formed a protective alumina or chromia scale and therefore they are likely to degrade rapidly without a protective coating.

\section{Coating MDC150L}

Comparison of the oxide scales formed on the coating system MDC150L and uncoated alloy CM186LC reveals that the oxide layer is much reduced for the coating system, even for extended total oxidation periods up to 82 hours. At $870^{\circ} \mathrm{C}$, the thickness of the oxide growth on the coating was found to be $0.95 \mu \mathrm{m}$ for an oxidation period of 82 hours, whereas at $826^{\circ} \mathrm{C}$, the uncoated CM186LC formed an oxide of thickness $1.2 \mu \mathrm{m}$ for an oxidation period of 22 hours. This is because the coating system is able to form a protective $\mathrm{Al}_{2} \mathrm{O}_{3}$ scale, which acts as a barrier against the highly damaging environment. Table 4 shows that the avcrage oxide growth for the alumina scale that forms on the coating drops from $0.50 \mathrm{~nm} / \mathrm{min}$ for a total oxidation period of 20 hours, to $0.19 \mathrm{~nm} / \mathrm{min}$ for a total oxidation period of 82 hours. This drop in oxide growth rate indicates the effectiveness of the alumina scale to as a barrier to further oxidation.

The high resolution imaging and isotopic oxygen mapping performed using the FIB200 provided direct characterisation of the oxidation growth mechanisms that occur at $870^{\circ} \mathrm{C}$ in 20 hours in air and 62 hours in oxygen 18. Figure 6 is a secondary electron image of the crater wall that has formed after depth profiling. This reveals the whisker like surface morphology which is characteristic of $\theta-\mathrm{Al}_{2} \mathrm{O}_{3}$ and has been observed by others [24]. Figure 8 is a secondary ion image showing the ion milled crater on the oxidised surface and the platinum deposit. The oxygen 16 and oxygen 18 maps are shown in figures 10 and 11 




Figure 12: MDC150L Isotopic Ratio Map Oxidation for: 20 hours in air +62 hours in ${ }^{18} \mathrm{O}_{2}$ at $870^{\circ} \mathrm{C}$.



Figure 13: Isotopic Ratio Profile for coating MDC150L obtained via depth profiling for sample oxidised as above. The isotopic fractions are given by: $i r_{18}=\frac{{ }^{18} \mathrm{O}^{-}}{{ }^{18} \mathrm{O}^{-}+{ }^{16} \mathrm{O}^{-}}$and $i r_{16}=1-i r_{18}$.

The isotopic ratio map that is shown in figure 12 above was determined directly from the oxygen 16 and oxygen 18 maps. The FIB oxygen mapping technique provides very localised information regarding the oxidation mechanism of a very specific area of interest and can be used to compare any isotopic oxygen difference in the oxide scale formed at the coating grain and grain boundary. The results obtained from the isotopic ratio maps are in good agreement with the isotopic fraction profile that was obtained by depth profiling, which is shown in figure 13. This shows that for oxidation treatments at $870^{\circ} \mathrm{C}$, the oxygen 18 isotopic ratio is high at the gas-oxide interface and hence relates to outward cation diffusion. This is true for all the oxidation treatments irrespective of oxidation time.

\section{Conclusion}

These promising results obtained have emphasised the usefulness of Secondary Ion Mass Spectroscopy and the Focused Ion Beam technique in elucidating the high temperature oxidation of nickel base superalloys and protective coatings. Alloy CM186LC displayed outward cation diffusion for all temperatures between $826^{\circ} \mathrm{C}$ and $1100^{\circ} \mathrm{C}$, whereas $\mathrm{CMSX} 4$ has shown a change in mechanism. At temperatures between $826^{\circ} \mathrm{C}$ and $906^{\circ} \mathrm{C}$, this alloy displays outward cation diffusion, whereas at $996^{\circ} \mathrm{C}$ a combination of inward oxygen and outward cation diffusion is observed. Neither alloy formed a protective oxide scale. The coating system MDC150L displayed outward cation diffusion at $870^{\circ} \mathrm{C}$ for oxidation periods up to 82 hours and formed a effective alumina scale. The tracer enrichment profiles that were obtained for the uncoated superalloys provide useful information regarding the oxidation mechanisms that occur during oxide evolution. Their respective cation depth profiles provide detailed information regarding the compositional nature of the thermally grown scale. The high resolution and in-situ milling capabilities of the FIB system have been particularly useful in characterising the oxide formed on the coated system MDC150L. Oxygen isotopic ratio maps give direct information regarding the diffusion mechanism and are free from errors associated with depth calibration of depth profiles.

This encouraging application of secondary ion mass spectrometry and the focused ion beam technique has clearly established the usefulness of such analyses in determining the high temperature oxidation of superalloy materials and protective coatings.

\section{Acknowledgements}

The authors wish to acknowledge R.Chater for his help and advice with the SIMS analyses and J.Walker from FEI-Europe for his assistance with the FIB experiments. Financial support for this project was provided by the Engineering and Physical Science Research Council, UK.

\section{$\underline{\text { References }}$}

[1]T.N. Rhys-Jones, "Protective Oxide Coatings on Superalloys and Coatings Used in Gas Turbine and Vane Applications." Mat. Sci. \& Tech, 4, (1988), 421-430.

[2]J.Jedlinski, G.Borchardt and S. Mrowec, "Transport Properties of Alumina Scales on the $\beta-\mathrm{NiAl}$ Intermetallic" Solid State Ionics, 50, (1992), 67-74

[3]B.A. Pint, J.R. Martin and L.W Hobbs, “ ${ }^{18} \mathrm{O}$ SIMS Characterisation of the growth mechanism of doped and undoped $\alpha-\mathrm{Al}_{2} \mathrm{O}_{3}$," Oxidation of Metals, 39, (1993), 167

[4]H.M Tawancy, N. Sridhar and N.M Abbas, "Failure Mechanism of a Thermal Barrier Coating on a Nickel-Base Superalloy" Journal of Mat.Sci, 33, (1998), 681-686.

[5]A.M Freborg et al., "Modelling Oxidation Induced Stresses In Thermal Barrier Coatings" Mat Sci \& Engineering A, A245, (1998), 182-190.

[6]B.A. Pint et al., "Substrate and Bond Coat Compositions: Factors Affecting Alumina Scale Adhesion" Mat Sci \& Eng A, VolA245, (1998) pp.201-211.

[7]H Caspari,. "Protective coatings extend gas turbine life and efficiency." Reprinted from Power Generation Technology (1995) for Sermatech International Inc.

[8]P Sahoo and G.W Goward.: "On the suitability and application of MCrAlY coatings under various operating conditions". Thermal Spray Industrial Applications - (paper presented at the $8^{\text {th }}$ National Thermal Spray Conference, Houston, Texas, September 11-15, 1995), 539-544.

[9]M.J Graham.: "The study of oxide scales using SIMS", Microscopy of Oxidation. Institute of Materials, No. 500, 10-18. 
[10]J Doychak.: "Oxidation behaviour of high-temperature intermetallics.," Intermetallic Compounds, (John Wiley \& Sons, 1994), vol. 1, chap. 43.

[11] W.J Quadakkers. et al, "Effect of the $\theta$ alumina formation on the growth kinetics of alumina-forming superalloys". Oxidation of Metals. 46, (5/6), (1996), 465-480.

[12] G Borchardt., J Jedlinski. and W Wegener, "Oxygen-18 tracer diffusion as a tool to study high temperature oxidation of metals". (In Proceedings of the 8th. Secondary Ion Mass Spectrometry, Amsterdam, The Netherlands, September $15-20^{\text {th }}$ 1991), 737-740.

[13] J Doychak. and J.L Smialek. "Transient oxidation of single crystal $\beta$-NiAl". Metal. Trans. 20A, (1989), 499.

[14] P.T Mosely et al,. "The microstructure of the scale formed during the high temperature oxidation of Fecralloy steel" Corrosion. Science., vol. 24, 1984, p. 547.

[15] D.Garriga-Majo et al., "Novel strategies for evaluating the degradation of protective coatings on superalloys" Jounal of Inorganic Materials, 1, (1999), 325-336

[16] A.Alibhai, D.McPhail, B.A Shollock, "Use of isotopic tracers and SIMS analysis for evaluating the high temperature degradation of protective coatings on nickel based superalloys" (In Proceedings of the 12th. Secondary Ion Mass Spectrometry, Brussels 1999).

[17] K Robinson et al. "Applications of focused ion beam milling in biological electron microscopy". Microsc. and Analysis., (1997), 15-16

[18]N. Presser and M.R Hilton, "Applications of focused ion beam machining to the characterisation of carbide, nitride and oxide films," Thin Solid Films, 308, (1997), 369-374

[19]F Wang, P Garoche and L Dumoulin, "Focused ion beam imaging of grains in Al-Li-Cu quasicrystal," Journal. Of PhysicsCondensed Matter, 10, (16), (1998), 3479-3488.

[20]B.M. Warnes and D. Punola, "Clean diffusion coatings by chemical vapour deposition," Surface and Coatings Technology, 94-95, (1997), 1-6.

[21]S.N.Basu and J.W. Halloran, "Tracer isotope distribution in growing oxide scales," Oxidation of Metals, 27, (3/4), (1987), 142-155.

[22]P.S. Burkholder et al., "CM186LC alloy single crystal turbine vanes," (International Gas Turbine and Aeroengine congress and exhibition, Indianapolis, Indiana, 7-10 June 1999).

[23]P.S. Korinko, M.J. Barber and M. Thomas, "Coating Characterisation and Evaluation of Directionally Solidified CM186LC and Singlc Crystal CMSX4," (ASME Turbo EXPO 1996, NEC, Birmingham, UK).

[24]G.C. Rybicki and J.L Smialek, "Effect of the $\theta-\alpha-\mathrm{Al}_{2} \mathrm{O}_{3}$ transformation on the oxidation behaviour of $\beta-\mathrm{NiAl}+\mathrm{Zr}$," Oxidation Of Metals, 31,(3/4), (1989), 275-304. 